Faculdade

de Ciências Econômicas UFRGS
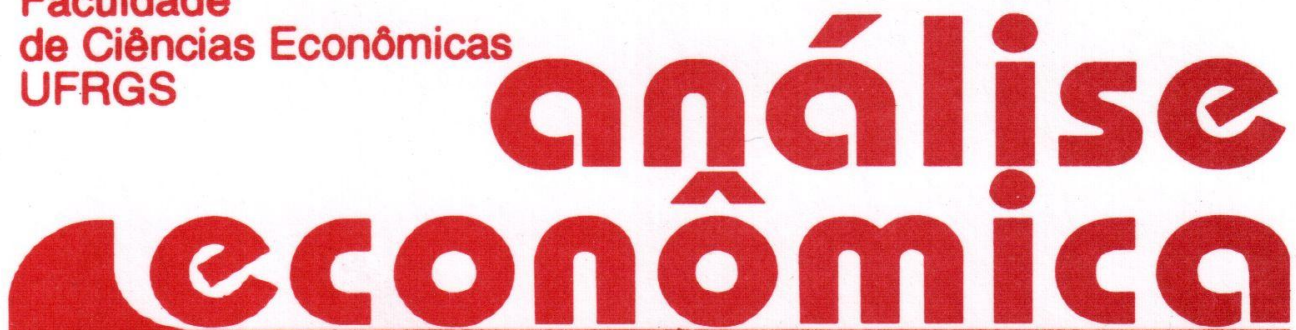

- SIDERURGIA E O PARADIGMA TECNOLÓGICO

Angela Maria Morandi

- ESTIMATING PRIVATE DEMANDS FOR PUBLIC GOODS

Eduardo Pontual Ribeiro

- KEYNES E A ATUALIDADE DA TEORIA KEYNESIANA

Fernando Ferrari Filho

- IMPRODUTIVIDADE DE UM CONCEITO DE PRODUÇÃO Raul Cristóvão dos Santos

- A NEGAÇÃo dA INEFICÁCIA DA POLÍTICA MONETÁRIA João Sicsú

- DESREgulamentAÇÃo, globa LIZAÇÃo E A CADEIA DO TRIGO Lena Lavinas

Manoel Magina

- ALUGUÉIS RESIDENCIAIS EM PORTO ALEGRE

Marco Aurélio Stumpf González

- POLICY INTERVENTION AND THE TRADE-OFF BETWEEN GROWTH AND DISTRIBUTION OF INCOME Joanílio Rodolpho Teixeira Jorge Thompson Araujo

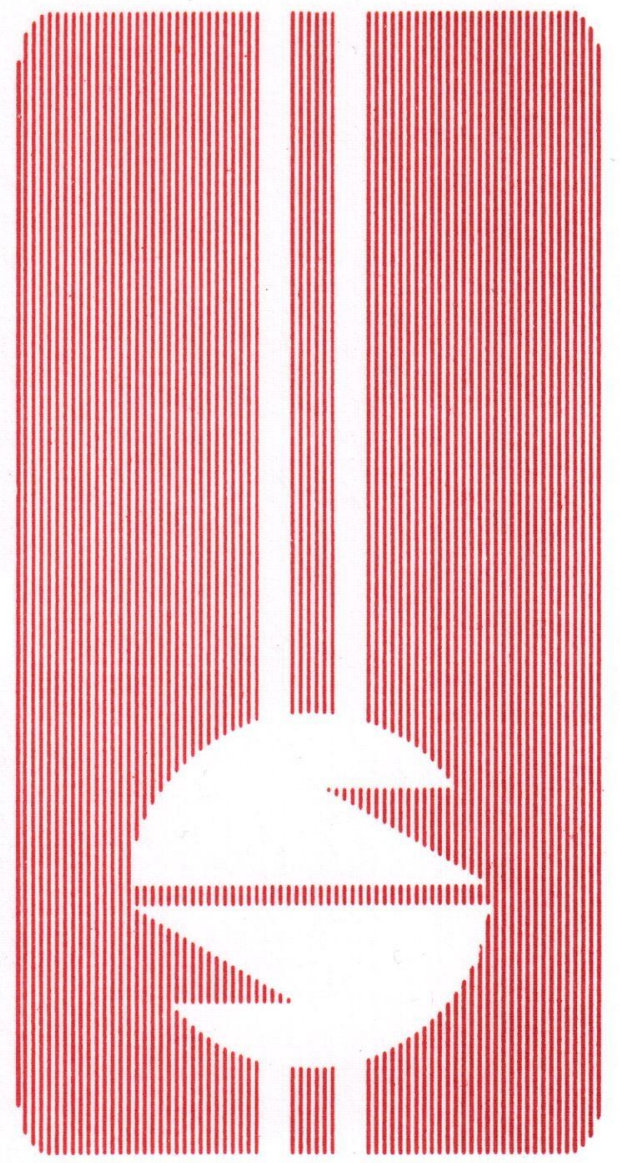


UNIVERSIDADE FEDERAL DO RIO GRANDE DO SUL

Reitora: Prof ${ }^{a}$. Wrana Maria Panizzi

FACULDADE DE CIENNCIAS ECONÓMICAS

Diretora: Prof ${ }^{\mathrm{a}}$. Otilia Beatriz Kroeff Carrion

CENTRO DE ESTUDOS E PEQUISAS ECONÔMICAS

Diretor. Prof. Fernando Ferrari Filho

DEPARTAMENTO DE CIÊNCIAS ECONÓMICAS

Chefe: Prof. Gentil Corazza

CURSO DE PÓS-GRADUAÇÃO EM ECONOMIA

Coordenador. Prof. Marcelo Savino Portugal

CURSO DE PÓS-GRADUAÇÃO EM ECONOMIA RURAL

Coordenador: Prof. Carlos Guilherme A. Mielitz Netto

CONSELHO EDITORIAL: Achyles B. Costa, Aray M. Feldens, Carlos A. Crusius, Carlos G. A. Mielitz Netto, Eduardo A. Maldonado Filho, Eduardo P. Ribeiro, Eugênio Lagemann, Fernando Ferrari Filho, Gentil Corazza, Marcelo S. Portugal, Nali J. Souza, Otília B. K. Carrion, Paulo A. Spohr, Paulo D. Waquil, Pedro C. D. Fonseca, Roberto C. Moraes, Ronald Otto Hillbrecht, Stefano Florissi, Eleutério F. S. Prado (USP), Fernando H. Barbosa (FGV/RJ), Gustavo Franco (PUC/RJ), João R. Sanson (UFSC), Joaquim P. Andrade (UnB), Juan H. Moldau (USP), Paul Davidson (Univ. of Tennessee), Werner Baer (Univ. of Illinois).

COMISSÃO EDITORIAL: Eduardo Augusto Maldonado Filho, Fernando Ferrari Filho, Gentil Corazza, Paulo Dabdab Waquil, Marcelo Savino Portugal, Roberto Camps Moraes.

EDITOR: Nali de Jesus de Souza

SECRETARIA: Cláudia Porto Silveira, Sandra Mascarello e Fábio Régis Sparremberger. Revisão de textos: Vanete Ricacheski.

FUNDADOR: Prof. Antônio Carlos Santos Rosa

Os materiais publicados na revista Análise Económica são da exclusiva responsabilidade dos autores. É permitida a reprodução total ou parcial dos trabalhos, desde que seja citada a fonte. Aceita-se permuta com revistas congêneres. Aceitam-se, também, livros para divulgação, elaboração de resenhas e recensões. Toda correspondência, material para publicação (vide normas na terceira capa), assinaturas e permutas devem ser dirigidos ao seguinte destinatário:

PROF. NALI DE JESUS DE SOUZA

Revista Análise Econômica - Av. João Pessoa, 52

CEP 90040-000 PORTO ALEGRE - RS, BRASIL

Telefones: (051) 316-3348 e 316-3440 - Fax: (051) 316-3990

nali@vortex.ufrgs.br 


\title{
A IMPRODUTIVIDADE DE UM CONCEITO DE PRODUÇÃO*
}

\author{
Raul Cristovão dos Santos
}

\begin{abstract}
SINOPSE
Este artigo examina o conteúdo conceitual do argumento formal de Hahn o qual afirma que o modelo de Sraffa é um caso particular do modelo de equilíbrio geral Argumenta-se que esta afirmativa não é plausivel porque os conceitos de produção dos dois modelos não são equivalentes. Assim, a taxa de retorno e os preços determinados por Hahn refletem tãosomente a questão da alocação intertemporal das dotaçôes iniciais dos agentes, e não a questão básica posta pela Economia Política da distribuição do excedente de forma a tornar possivel a reprodução do sistema econômico
\end{abstract}

Cód. AEA: 030

Palavras-Chave: Sraffa; produção como reprodução; preços de produçăo;

\section{ABSTRACT}

This article examines the conceptual content of Hahn's formal argument which asserts that Sraffa's model is a particular case of the general equilibrium model. It argues that this proposition is untenable since these models analyzed different concepts of production. Thus, the rate of return and prices determined by Hahn are just simple expressions of the economic agents'problem in allocating intertemporally their initial endowments, and not that of Political Economy of the distribution of surplus in order to the economic system to reproduce itself.

Cód. AEA: 030

Key words: Sraffa; production as reproduction; prices of production.

Este artigo foi gerado no âmbito do Programa de Apoio à Pesquisa Acadêmica (PAPA) do Departamento de Economia da FEA-USP com o apoio financeiro da Fundação instituto de Pesquisas Econômicas da Universidade de São Paulo, FIPE-USP Aproveito para agradecer ao Prof Jorge E J Soromenho pelas discussões de alguns temas penosos acerca das diferenças teóricas entre as matrizes clássica e marginalista. No entanto, erros e equívocos são de minha inteira responsabilidade

"Professor da FEA-USP.

\begin{tabular}{|l|l|l|l|l|}
\hline ANÁLISE ECONÔMICA & ANO 15 & N. 28 & Setembro/97 & p. $59-79$ \\
\hline
\end{tabular}




\section{INTRODUÇÃO}

Este artigo examina os aspectos conceituais do argumento formal de Hahn que afirma ser o modelo de Sraffa um caso particular do modelo de equilíbrio geral. Tentar-se-á mostrar que esta conclusão só é possivel graças ao deslocamento do conceito de produção de Sraffa realizado por Hahn na construção formal dos modelos de equilíbrio geral e de Sraffa.

Inicialmente, convém ressaltar que não se tenciona discutir a querela de Hahn com os neo-ricardianos. Pelo contrário, o propósito é questionar a sua interpretação de Sraffa como inadequada por distorcer a estrutura teórica da Economia Política, em particular, a natureza e o papel do conceito de produção nesta estrutura. Aliás, deste ponto de vista, estabelece-se aqui uma crítica implícita à corrente neo-ricardiana exatamente porque esta também desvincula o argumento formal de Sraffa daquela estrutura. Por fim, para evitar outros mal-entendidos, entende-se aqui por Economia Política ou Economia Clássica, a construção conceitual elaborada por James Mill, a partir da concepção de Say, e que serviu de arcabouço aos trabalhos de Ricardo.

Esta construção recebeu sua forma final, se adequada ou não é uma outra questão, na obra de John Stuart Mill. De maneira geral, concebe-se o estudo da produção e distribuição da riqueza como o objeto da ciência econômica. Por sua vez, riqueza é definida como o conjunto de objetos úteis que requerem algum tipo de esforço humano na sua obtenção. Portanto, em nenhum momento, subentende-se aqui por Economia Política a construção teórica de Marx. A esta reservamos o devido espaço enquanto discurso crítico da própria Economia Política.

Então, dado ser o objetivo deste artigo questionar, do ponto de vista conceitual, a interpretação de Hahn sobre a construção teórica de Sraffa, optou-se pelo seguinte procedimento: discutir estas questões conforme elas se apresentam em cada etapa do argumento formal de Hahn. Assim, a primeira seção apresenta o modelo de Sraffa segundo Hahn e, ao fazê-lo, aponta para a omissão dos conceitos centrais do discurso da Economia Política: as idéias de reprodução e de excedente. A segunda seção, seguindo o argumento de Hahn, volta-se para a construção teórica do modelo de equilíbrio geral. Aqui, o ponto crucial está na forma como produção, enquanto fenômeno econômico, é introduzida no núcleo conceitual marginalista. A terceira seção discute o procedimento de Hahn de fazer o modelo marginalista fornecer respostas às questões postas pelo modelo de Sraffa. Notar-se-á que, a despeito da similaridade formal, estas

${ }^{1}$ Veja-se Mill (1979, p. 300-308). 
respostas são conceitualmente distintas daquelas referentes a Sraffa. $O$ procedimento formal de Hahn equivale a uma distorção do conceito de produção como empregado por Sraffa. Na seção final, procede-se a um balanço dos resultados, apontados ao longo das seções anteriores.

\section{SRAFFA SEGUNDO HAHN}

A primeira etapa do argumento de Hahn $\left(1982\right.$, p.354-58) ${ }^{2}$ inicia com a exposição do sistema de quantidade do modelo de Sraffa. Em um modelo de duas mercadorias, 1 e 2 , suas condições de produção são dadas pela soma das quantidades empregadas de cada uma delas, incluindo a quantidade de cada uma consumida na produção de si mesma, mais a quantidade de trabalho que entra na sua produção. Estas relações são expressas por:

$$
\sum_{j} a_{i, j} x_{j} \text { e } \sum_{j} a_{i, j} x_{j}
$$

assumindo que $a_{i j}>0$ e $a_{0 i}>0$.

O sistema padrão de Sraffa é obtido do sistema original, considerando o caso no qual a proporção dos insumos utilizados é a mesma dos produtos gerados. Assim, neste caso:

$$
\begin{aligned}
& \frac{\sum_{j} a_{2 j} x_{j}^{*}}{\sum_{j} a_{1 j} x_{j}^{*}}=\frac{x_{2}^{*}}{x_{1}^{*}} \\
& \frac{x_{1}^{*}}{\sum_{j} a_{1 j} x_{j}^{*}}=\frac{x_{2}^{*}}{\sum_{j} a_{2 j} x_{j}^{*}}=G^{*}
\end{aligned}
$$

onde $x_{i}$ representa as quantidades dos produtos no Sistema Padrão e $G^{\star}$, a proporção requerida.

Na notação matricial, o Sistema Padrão pode ser escrito como:

2 Utilizo aqui o artigo original publicado no Cambridge Journal of Economics, ver Hahn (1982). Existe uma tradução deste artigo em Hahn (1991) feita pelo Prof. Roberto Camps de Moraes, do Curso de Pós-Graduação em Economia da UFRGS 


$$
\begin{aligned}
& {\left[\begin{array}{l}
x_{1}^{*} \\
x_{2}^{*}
\end{array}\right]=G^{*}\left[\begin{array}{ll}
a_{11} & a_{12} \\
a_{21} & a_{22}
\end{array}\right]\left[\begin{array}{l}
x_{1}^{*} \\
x_{2}^{*}
\end{array}\right]} \\
& \underline{x}^{*}=G^{*} A x^{*} \\
& \underline{A x}^{*}=\left(1 / G^{*}\right) \underline{x}^{*}
\end{aligned}
$$

Os autovalores da matriz A de coeficientes técnicos fornecerá os possiveis valores de $G^{*}$. Neste caso, associados a cada um dos dois autovalores estarão os autovetores correspondentes $x^{*}=\left(x_{1} ; x_{2}\right)^{\top}$ de $\underline{A}$ que são a solução para o Sistema Padrão. De fato, como $a_{i j}>0$ e $1-\Sigma a_{i j}>0$ para $\mathrm{j}=1,2$ (há um excedente de produtos acima das quantidades destes gastas na produção) somente um autovalor , o maior, será escolhido e a solução correspondente, $\left(\lambda_{1}^{*}, \lambda_{2}^{*}\right)$. As soluções $\left(\lambda_{1}^{*}, \lambda_{2}^{*}\right)$ somente mostram as quantidades relativas das mercadorias $x_{1}$ e $x_{2}$ a serem produzidas no Sistema Padrão. Para encontrar a quantidade absoluta de cada bem supõe-se que se gasta toda a soma de trabalho disponível na produção de ambos os bens. ${ }^{3} \mathrm{Com}$ uma quantidade de trabalho igual a 1 , pode-se escrever esta condição como:

$$
\begin{aligned}
& k \sum \mathrm{a}_{0, j} \lambda_{\mathrm{j}}^{*}=1 \quad, \quad \mathrm{k}>0, \quad \mathrm{j}=1,2 \quad \mathrm{e} \\
& \mathrm{x}_{\mathrm{i}}^{*}=\mathrm{k} \lambda_{\mathrm{i}}^{*}, \quad \mathrm{i}=1,2
\end{aligned}
$$

A mercadoria composta, $x^{*}=\left(x_{1}^{*}, x_{2}^{*}\right)$, é então definida como UMA UNIDADE DA MERCADORIA PADRÃO. A proporção $G^{\star}$ requerida será maior que 1 e resulta na taxa UNIFORME de excedente do sistema. Assim:

$$
G^{*}=\left(1+g^{*}\right)
$$

Retornando ao sistema de preços, para uma dada taxa de lucro, os preços serão dados por.

$p_{j}=R \sum a_{i j} p_{i}+a_{0 j} w, \quad j=1,2$

onde $R=(1+r), r$ é a taxa uniforme de lucro e $w$ a taxa de salário por

\footnotetext{
${ }^{3}$ Note-se que Sraffa, seguindo o procedimento clássico, utiliza aqui a quantidade empregada de trabalho.

62
} 
unidade de trabalho. Em notação matricial:

$$
\begin{aligned}
& {\left[\begin{array}{l}
p_{1} \\
p_{2}
\end{array}\right]^{\mathrm{r}}=(1+r)\left[\begin{array}{l}
p_{1} \\
p_{2}
\end{array}\right]^{\mathrm{r}}\left[\begin{array}{ll}
\mathrm{a}_{11} & \mathrm{a}_{12} \\
\mathrm{a}_{21} & a_{22}
\end{array}\right]+\left[\begin{array}{l}
\mathrm{a}_{01} \\
a_{02}
\end{array}\right]^{\mathrm{T}} \mathrm{W}} \\
& \underline{\mathrm{p}}=\operatorname{RpA}+\mathrm{a}_{0} \mathrm{w} \\
& \mathrm{p}_{1}+\mathrm{p}_{2}+\mathrm{w}=1
\end{aligned}
$$

Novamente, o maior autovalor resultará na taxa de lucro com preços não-negativos nas soluções que têm agora o auto-vetor de $\mathrm{A}$ associado ao autovalor relevante.

Hahn faz agora a nova normalização com o valor adicionado da mercadoria padrão $x{ }^{*}$ igual a 1. Assim, a equação (4) acima torna-se:

$\underline{\operatorname{PAx}}^{*}+w=1$

O sistema de preço dado pelas equações (3) e (4') terão $P(r)$ e w(r) como soluções para uma dada taxa de lucro, r. Da equação (1):

$P(r) \underline{x}^{*}=G^{*} P(r) \underline{A x}{ }^{*}$

$P(r) \underline{x}^{*}=\left(1+g^{*}\right) P(r) \underline{A x} \underline{x}^{*}$

$P(r) \underline{x}^{*}=P(r) \underline{A x}^{*}+g^{*} P(r) \underline{A x} \underline{x}^{*} \quad$ então,

$g^{*}=\frac{p(r) \underline{x}^{*}-p(r) \underline{A x}}{p(r) \underline{A x} \underline{x}^{*}}$

Desde que a solução satisfaça a equação (4') que diz que o valor adicionado da mercadoria padrão é igual a $1, p(r) \underline{x}^{*}-p(r) \underline{A x^{*}}=1$, então, $g^{*}=1 / p(r) \underline{A x^{*}}$ ou $p(r) \underline{A x^{*}}=1 / g^{*}$

Assim, na equação (4'):

$$
\begin{aligned}
& r\left(1 / g^{*}\right)+w=1 \\
& r=g^{*}(1-w)
\end{aligned}
$$

Utilizando a equação (4') em vez da equação (4), a relação entre a taxa 
de lucro e a taxa de salário é linear. Para Hahn, este é o único mérito da expressão (4'), uma simples normalização como qualquer outra, sem qualquer conexão com a questão do valor.

Muito embora Hahn faça uma apresentação formal elegante do modelo de Sraffa, esta está desconectada da estrutura teórica da Economia Política, quase como se a mera formalização tornasse irrelevante o seu conteúdo conceitual. No entanto, de acordo com o próprio Sraffa, o seu trabalho deriva desta matriz teórica e nela se inspira. Conforme aponta Sraffa, a concepção do processo econômico como um processo circular origina-se no Tableau de Quesnay. De fato, a concepção de que o sistema econômico contém uma lógica própria foi sendo refinada a partir do Tableau por Turgot e, principalmente, Say. Na Inglaterra, James Mill o adota e constrói o arcabouço básico da Economia Política que passa a se definir como o estudo da produção e distribuição da riqueza. Deve-se então, neste ponto, resgatar esta estrutura, no mínimo porque a construção teórica da Economia Política distingue-se radicalmente daquilo que se pratica hoje no interior da ciência econômica.

$O$ ponto de partida da ciência econômica estabelece-se na relação entre necessidades humanas e objetos que satisfazem estas necessidades. A Economia Política aponta que os indivíduos devem despender algum esforço para obter estes objetos desde que estes não se encontram prontos para atender estas necessidades. O "econômico" da vida social define-se por esta inevitabilidade de um esforço humano para obter os objetos úteis necessários à sobrevivência da espécie humana. ${ }^{5}$ Como já afirmava Quesnay, subsistência é a questão básica dos estudos dos homens na sua vida social. ${ }^{6}$ Produção ou trabalho humano é a condição global que permeia a existência dos indivíduos em sociedade. $O$ conjunto de ações humanas orientadas na aquisição de objetos úteis (riqueza) através deste esforço forma o sistema econômico. ${ }^{7}$ Desta perspectiva emerge outra característica importante na estrutura teórica da Economia Política. Nesta, não são os indivíduos, tomados isoladamente ou em sociedade, que se apresentam como os agentes destas ações, mas sim os indivíduos considerados em

\footnotetext{
${ }^{4}$ Ver introdução e apêndice D em Sraffa (1960).

${ }^{5}$ É exatamente porque a satisfação de necessidades humanas impōe o trabalho ou a produção como o "econômico" da vida social que nenhum elemento de demanda entra na análise clássica. A ausência destes elementos sempre foi um motivo de insatisfação em qualquer avaliação do pensamento clássico feita por autores marginalistas conforme atestam Schumpeter (1954, p.309, 601-2) e Kauder (1960, p. 282).

6 Quesnay (1963, p.66). Veja-se tambem Smith (1982, p.333-340), para quem as necessidades humanas predispunham os homens à indústria, quer dizer, ao trabalho

7 Uma exposição clara e concisa desta concepção do econômico encontra-se em Mill (1826, p. 210-211)
} 
classes de acordo com a sua posição no interior da produção. Em outras palavras, da perspectiva da produção enquanto condição global de existência dos indivíduos, estes passam a ser diferenciados pelo papel que desempenham no processo de produção de acordo com a propriedade que têm sobre os elementos indispensáveis à produção. ${ }^{8}$ De maneira geral, estes elementos são o próprio trabalho humano, condições de trabalho (materiais, instrumentos, subsistência dos indivíduos engajados na produção), e terra enquanto fonte primária de todos estes elementos. A idéia crucial, e tomada como natural, ${ }^{9}$ é a de que as condições de trabalho encontram-se concentradas num pequeno grupo de indivíduos, denominados capitalistas. Da mesma forma, a terra é propriedade de outro reduzido grupo de indivíduos, os proprietários de terra. Por fim, o restante dos indivíduos se diferencia pela propriedade do trabalho e compõe a classe dos trabalhadores. Estes formam a maior destas três classes conforme apontava Smith. A primeira delas cabe o papel de organizar e dirigir a produção através do adiantamento das condições para que a última classe execute sua função, a ação de transformar aqueles materiais com a ajuda de instrumentos em produtos finais. A classe dos proprietários não participa deste processo exceto como fornecedora de um daqueles elementos. A propriedade da terra lhe confere um direito, por assim dizer, à parte do produto. Assim, estas três classes econômicas definem os agentes e as respectivas ações humanas orientadas para obter riqueza no arcabouço teórico da Economia Política.

A questão central é saber se uma sociedade ao produzir, ela consegue produzir de novo os elementos que the são indispensáveis à produção. Em outras palavras, a questão é saber se o sistema econômico tem condições de reproduzir-se ao longo do tempo. ${ }^{t 0}$ Caso ela atenda, afirma-se que seu sistema de produção é viável. Observe-se a estreita relação conceitual entre a condição de viabilidade e a idéia de produção como reprodução na estrutura teórica da Economia Política. ${ }^{11}$

\footnotetext{
${ }^{8}$ Ver Mill (1848, p. 238)

9 Marx (1976, p 174, n 34; p 175, n 35) aponta a naturalização da relação de produção capitalista como o principal limite da Economia Politica.

to Uma questão interessante é a relação entre a circularidade da produção e a circularidade do sistema econômico. Neste artigo sustenta-se que a primeira implica a última. Isto porque ao definir-se a produçăo como circular, mercadorias entram na produção delas mesmas, pode-se definir o excedente de produção e, assim, a capacidade que o sistema, como um todo, tem em se reproduzir. Veja-se Soromenho (1996) para um contraste entre estes conceitos e a teoria austríaca de produção.

${ }^{11}$ A primazia da idéia de reproduçăo na Economia Política foi devidamente ressaltada por Marx (1978, p.166) ao qualificar a análise clássica como correspondendo ao seu circuito do capital produtivo.
} 
Se o sistema econômico é viável, há ainda que considerar como os produtos gerados são distribuídos entre as três classes econômicas. Para a Economia Política, esta é a tarefa que o processo de circulação (mecanismo de trocas) realiza. Neste, as trocas distribuem o produto total entre as três classes de tal forma que o processo de produção possa ser reiniciado. As relações de troca entre as diversas mercadorias ou simplesmente, os seus preços, devem ser tais que permitam a reprodução do sistema. Portanto o processo econômico global consiste em dois periodos seqüenciais. O primeiro é o da produção em que são produzidas as mercadorias. O segundo é o da circulação onde as mercadorias produzidas são distribuídas entre as três classes econômicas. Esta ordem lógica do processo econômico reflete-se exatamente na concepção do domínio teórico da ciência e na sua ordem lógica da exposição: o estudo da produção e distribuição da riqueza. ${ }^{12}$

Sraffa segue fielmente a estrutura lógica da Economia Política ${ }^{13}$. Considere-se, por exemplo, a primeira página do seu livro. Aqui, Sraffa discute o caso mais simples, ou seja, quando o sistema produz exatamente aquilo que utiliza na produção (como meios de subsistência ou de produção). Ele inicia por especificar as condições de produção de uma economia de dois produtos. Esta economia atende a condição de viabilidade, pois as quantidades totais produzidas dos dois produtos são exatamente iguais as quantidades totais utilizadas das mesmas na produção. Em seguida, Sraffa reporta-se a determinação dos valores de troca destes bens, ou seja, ele considera o período de circulação desta economia. Sua conclusão é que se for adotado o conjunto de relações de troca apropriado (e único) então o processo de circulação distribui os produtos de forma a tornar possivel a repetição do processo de produção, (Sraffa, 1960, p.3). Na verdade, neste caso particular, os preços devem refletir exatamente as condições de produção.

Agora, o caso relevante para os economistas políticos é o da produção com excedente. Do lado das quantidades, isto quer dizer que pelo menos para uma mercadoria, a quantidade produzida desta é superior à quantidade dela consumida durante o período de produção. A condição de viabilidade é satisfeita como uma desigualdade estrita. Nesta caso, ocorre

\footnotetext{
${ }^{12}$ Ver Eagly (1974, p.43). Schumpeter (1954, p.564-65) descreve este modo de conceber o processo econômico como o de "economia sequencial" em contraste com a concepção "sincronizada" do mesmo. Note-se, porém, que a característica marcante da primeira concepção está na idéia de adiantamentos.

${ }^{13}$ Deve-se lembrar que o referencial teórico de Sraffa é o da Economia Política, e nāo exclusivamente o da teoria da distribuição de Ricardo que, por sinal, compõe um dos blocos desta estrutura.
}

66 
uma questão adicional na determinação dos preços, pois agora, deve-se determinar como este será distribuído entre as classes econômicas. Sendo mais específico, exigi-se a determinação da taxa de lucro em conjunto com a determinação dos preços dos produtos. Note-se então que conceitualmente a taxa de lucro coloca-se como o 'dual' da existência de um excedente na esfiera de produção. Esta concepção teórica implica que, na estrutura teórica da Economia Política, seja especificado algum parâmetro distributivo para que este em conjunto com as condições de produção possa-se determinar os preços das mercadorias. Usualmente, e seguindo algumas proposições de Smith, Malthus e Ricardo acerca da determinação dos salários especifica-se a taxa de salário real. Sraffa, no entanto, sugere outra via: assumir como parâmetro distributivo a taxa de lucro. Esta taxa, enquanto uma razão, argumenta Sraffa, tem um significado que independe dos preços. Assim, ela pode ser determinada por algum fator externo do sistema de produção. Sraffa aponta para a taxa de juros como o possível determinante da taxa de lucro. ${ }^{14}$ Note-se que este argumento de Sraffa é familiar a algumas proposições da Economia Política. De fato, na sua análise das aplicações do capital no Reflections, ${ }^{15}$ Turgot assinala em primeiro lugar que a taxa de juros é determinada exclusivamente no mercado monetário e, portanto, independentemente das condições de produção. Em segundo lugar, assinala que esta taxa estabelece o limite inferior para a realização das demais aplicações do capital, tais como adquirir propriedade fundiária e, e este é o caso que interessa a Sraffa, aplicar na indústria ou comércio.

\section{PRODUÇÃO E O MODELO DE EQUILÍBRIO GERAL}

Vamos agora a segunda etapa do argumento de Hahn (1982, p.359-62) e que devota-se a elaboração do modelo de equilíbrio geral. Primeiro, assumindo retornos constantes de escala e sem produção conjunta, todas as combinações possiveis de insumos para produzir uma unidade de cada bem j, disponivel aos produtores, pode ser assim expressa:

$f_{j}\left(a_{1 j} ; a_{2 j} ; a_{0 j}\right)=1, j=1,2$

Consideraremos agora $A_{j}$ como sendo o conjunto de todas as atividades $a_{j}=\left(a_{1 j}, a_{2 j}, a_{0 j}\right)$ que satisfaz a expressão acima. Como é assumida a competição perfeita para todos os agentes $r$, w e preços são

\footnotetext{
${ }^{14}$ Sraffa (1960, p.33)

${ }^{15}$ Turgot $(1766$, p.81-2, 88). Sobre a teoria do capital de Turgot ver Groenegewem (1971) e Santos (1996).
} 
parâmetros. Assim, pode-se dizer que o comportamento racional dos agentes maximizará seus lucros e o modelo de insumo-produto e todos os preços relativos serão determinados. Cada agente trata $r, P$ e w parametricamente e cada um escolhe a técnica relevante para maximizar seu lucro. Então, dados (R, P, w), temos:

$$
\begin{array}{ll}
\mathrm{a}_{\mathrm{ij}}(\mathrm{R}, \mathrm{P}, \mathrm{w}) & \text { é uma solução para } \\
\operatorname{MAX} A_{j} & \mathrm{p}_{\mathrm{j}}-\mathrm{R}_{\mathrm{i}} \sum \mathrm{a}_{\mathrm{ij}} \mathrm{p}_{\mathrm{i}}-\mathrm{a}_{0 \mathrm{j}} \mathrm{w}
\end{array}
$$

Introduzindo a função de lucro unitário $\Pi(\ldots)$ - que expressa o lucro máximo por unidade de produto - a condição acima implica que o lucro máximo por unidade de output deve ser igual a zero (se $\Pi(\ldots)<0$, o bem não será produzido e se $\Pi(.)>$.0 , a taxa de lucro não será r). Então, temos o modelo completo dado por:

$$
\begin{aligned}
& \Pi_{j}(R, p, w)=0, \quad j=1,2 \\
& p_{1}+p_{2}+w=1
\end{aligned}
$$

Desde que $\mathrm{R}$ seja dado, o modelo tem três equações e três incógnitas. As duas atividades $a_{1}(R, p, w)$ e $a_{2}(R, P, w)$ foram determinadas ao mesmo tempo com as três incógnitas.

Entretanto, se a $\mathrm{f}_{\mathrm{j}}(\ldots)$ é uma função contínua, então $\mathrm{f}_{\mathrm{ji}}=\delta \mathrm{f}_{\mathrm{j}} / \delta \mathrm{a}_{\mathrm{ij}}$ dará a produtividade marginal do $\mathrm{i}^{\text {th }}$ insumo, e as condições para um lucro máximo, caso todos os insumos que estejam sendo utilizados, serão dadas por:

$p_{\mathrm{j}} f_{\mathrm{ji}}\left(a_{\mathrm{j}}\right)=R p_{\mathrm{i}}$

$p_{j} f_{j 0}\left(a_{j}\right)=w$,

isto é, o valor da produtividade marginal de cada insumo é igual (mas não determinado) à remuneração deles. Entretanto, como são assumidos retornos constantes de escala, temos

$$
f_{j i}\left(a_{j}\right) \cdot a_{i j}=1
$$

Agora, o modelo geral compõe-se das nove equações abaixo que, se existir uma solução, determinará as nove incógnitas (os quatro coeficientes $a_{i j}$, os dois coeficientes de trabalho $a_{0 j}$ os dois preços e a taxa de salário):

$p_{i} f_{j i}\left(a_{j}\right)=R p_{i}$ 
$p_{j} f_{j 0}\left(a_{j}\right)=w$

$\sum f_{i j}\left(a_{i j}\right) \cdot a_{i j}=1$

$p_{1}+p_{2}+w=1$

Até agora não há qualquer equação para determinar R. Hahn argumenta que o modelo marginalista é, neste ponto, igual ao modelo de Sraffa. Antes, porém, de apreciar como Hahn soluciona este impasse formal deve-se considerar a construção marginalista do conceito de produção.

Em primeiro lugar, produção tem um papel secundário na estrutura teórica do pensamento marginalista. Esta afirmativa pode causar espanto. Um difundido argumento marginalista diz que esta teoria é mais geral do que a da Econornia Política porque ela trata não só do lado da oferta (produção), que é o foco por excelência dos economistas políticos, mas também da demanda. ${ }^{16}$ Infelizmente, este não é o caso. O conceito de "econômico" da teoria marginalista prescinde de qualquer conceito de produção. ${ }^{17} \mathrm{O}$ seu núcleo teórico pode ser, e de fato o é, constituido independentemente de qualquer referência ao fenômeno da produção. A introdução da esfera de produção, o lado da oferta, ocorre como uma ampliação ou extensão do seu núcleo original. Esta ampliação ou extensão em nada altera a concepção analítica do sistema econômico como um sistema de trocas. Vejamos isto mais de perto.

Considere-se novamente o problema central da ciência econômica, a saber, a relação entre individuos e suas necessidades e os objetos que satisfazem estas necessidades. O pensamento marginalista constrói seu conceito de "econômico" ao afirmar que, nesta relação, os objetos úteis existem em quantidades inferiores àquelas necessárias para satisfazer as múltiplas necessidades dos indivíduos. Escassez é o "econômico" da vida social porque define uma condição global da existência dos indivíduos em sociedade. ${ }^{18}$ Note-se, em primeiro lugar, que a condição de escassez já está posta para um indivíduo considerado isoladamente. Não é necessário, conforme aponta Menger (1981, p.101), levar-se em conta o contexto social para se delinear o problema econômico como dado pelo o da escassez. Ora, dentro de tal concepção, são os indivíduos mesmos que se constituem como agentes econômicos. Em contraste com o pensamento clássico no

\footnotetext{
${ }^{16}$ Ver Arrow e Hahn $(1971$, p. 2).

17 Veja-se por exemplo Allingham (1983, p.5-6) que para apresentar a essência da teoria do valor marginalista, inicia por abstrair-se dos fenômenos da produção, capital e dinheiro.

${ }^{18}$ Ver Menger (1981, p.97), Walras (1984, p.65-66) e Robbins (1984)
} 
qual indivíduos contam na análise enquanto membros de classes econômicas, cujas "funções" no interior da produção determinam seus comportamentos econômicos, a concepção marginalista faz do indivíduo sua unidade básica de análise. ${ }^{19}$

Prosseguindo, a idéia de escassez delineia ou molda um tipo de ação, a saber, o ato de "economizar". Indivíduos devem escolher entre as alternativas quantidades de bens que satisfazem suas necessidades de acordo com suas preferências e que sejam factiveis dados os recursos escassos que possuem. Guiados pela ação "economizadora", cada indiwíduo está disposto a trocar sua dotação inicial por outra que the proporcione um maior grau de satisfação de suas necessidades. ${ }^{20}$ Assim, indivíduos trocam entre si suas dotações iniciais de bens. As trocas se constituem no mecanismo através do qual as escolhas individuais são executadas. Se não existe nenhum entrave neste mecanismo, indivíduos obtêm, ao final, uma cesta de bens diferente da dotação original, mas de igual valor, que lhes proporciona um grau de satisfação superior àquele que obteriam se não tivessem entrado em trocas. O sistema econômico é composto por este sistema de trocas calcado nas ações "economizadoras" dos indivíduos. Preços são as relações de troca entre quaisquer dois bens, estabelecidos pelos indivíduos no mercado, e nada mais são do que os indicadores da escassez relativa dos bens para os indivíduos, dado o seu conjunto de necessidades.

Formalmente, tem-se como parâmetros a dotação inicial de bens de cada indivíduo e a estrutura de suas necessidades. As variáveis a serem determinadas são as quantidades transacionadas e os preços. Estes, uma vez vigentes no sistema, estabelecem as trocas das dotações iniciais de forma que cada indivíduo maximiza o grau de satisfação.

Em segundo lugar, observe-se que se parte dos bens já prontos para consumo e que, portanto, não precisam ser produzidos. Produzi-los não faz parte do "econômico" da vida social que é dado pela escassez. ${ }^{21}$ Nenhuma referência à produção é feita, no modelo acima, de trocas puras. No entanto, afirma-se que este é apenas uma primeira aproximação ao complexo do mundo econômico. Conforme Walras (1984, p.211), uma

\footnotetext{
${ }^{19}$ Ver Dasgupta (1985, p 82)

20 Observe-se que esta formulação de ação econômica ajusta-se formalmente ao exercício matemático de maximizar uma função objetivo sujeita a alguma restrição. Daí ser a pedra de toque da teoria marginalista o conceito de utilidade marginal que possibilita a solução do suposto paradoxo da água e do diamante. Veja-se Ingrao e Israel (1990, p 91 -3).

21 Parte da estratégia de subsumir a Economia Política ao pensamento marginalista consiste precisamente em apagar a diferença entre os seus conceitos de "econômico". Deve-se, no entanto, lembrar que existem exceções notáveis no campo marginalista, como, por exemplo, Myint (1965)
} 
melhor aproximação à realidade requer pensar que os bens não se encontram produzidos, mas devem ser produzidos. $E$ isto abre o espaço teórico para se introduzir a esfera produtiva no modelo simples, tornando-o mais "real". Agora, esta operação não descarta a dotação inicial como parâmetro do modelo. Ela somente altera o seu conteúdo. Ao invés de consistir-se de quantidades de bens, as dotações iniciais são especificadas em quantidades de insumos ou de serviços dos fatores de produção. Estes fatores são teoricamente diferenciados dos produtos finais. Feita esta alteração nos dados iniciais do modelo, torna-se necessário um segundo parâmetro que especifique como estes insumos geram produtos. Este requisito é preenchido com a introdução do conjunto de técnicas disponiveis que descrevem as diferentes combinações de quantidades de insumos necessárias para gerar uma determinada quantidade de produto final. Produção consiste num processo unidirecional que parte dos insumos para produtos finais. Daqui, a necessidade de se distinguir conceitualmente insumos de bens finais.

De acordo com este novo quadro, os indivíduos devem agora estabelecer não só planos de consumo enquanto agentes consumidores, mas também planos de produção acerca de quanto devem produzir de produtos finais. Estes planos devem respeitar a condição de que a cesta de bens produzidos esteja dentro do conjunto possivel de cestas dado pelos métodos disponiveis para transformar insumos em produtos finais. Note-se a importância desta condição. Ela expressa quase tudo que se entende por produção na teoria marginalista. Insumos são transformados em produtos finais. Esta transformação é descrita pelas diferentes combinações de insumos para se gerar uma unidade de produto final. Assim, a questão relevante dentro desta concepção é saber quais destas combinações são possiveis ou não, dados os métodos de produção e a disponibilidade de insumos ou serviços dos fatores especificados como parâmetros do modelo. Note-se o flagrante contraste entre a condição de possibilidade técnica da produção do pensamento marginalista com a condição de viabilidade da estrutura teórica da Economia Política. A divergência entre ambas decorre da divergência conceitual entre produção como reprodução e produção como transformação unidirecional de insumos em bens finais. Na produção, a questão da escassez está presente na oferta limitada de fatores para produzir quantidades de bens. Na verdade, está-se diante do mesmo problema exposto acima entre necessidades humanas e disponibilidade de bens para atendê-las. Altera-se simplesmente o ponto de partida. As quantidades de insumos é que agora não são suficientes para gerar quantidades de bens que atendam aquelas necessidades. Assim, indivíduos enquanto produtores devem também "economizar". Isto quer dizer que eles devem utilizar a menor quantidade de insumos para obter 
uma dada quantidade final de produto ou, alternativamente, para uma dada quantidade de insumo, um maior nivel de produção. Sob esta conduta, prova-se que os indivíduos acabam por escolher a melhor combinação de insumos (técnica de produção) dentre aquelas existentes (tecnologia).

Uma vez de posse dos bens, os indivíduos executam as trocas nos moldes do modelo de trocas puras, descrito acima. Assim, em relação à formulação original, o modelo que inclui produção, não altera em nada a lógica do sistema econômico. E nem poderia, pois a concepção de econômico permanece inalterada. Só que agora, ao invés das trocas diretas, ou seja, entre bens, têm-se trocas indiretas entre quantidades de insumos e bens finais. Produção aparece como um passo intermediário entre insumos e produtos finais, por assim dizer, um caminho indireto para se realizar o processo central que são as trocas diretas entre bens pelos individuos "economizadores". Por isso, produção não funda ou não se constitui em fundamento da concepção do econômico no pensamento marginalista A introdução da produção como uma troca indireta deixa inalterado o significado teórico dos preços. No que diz respeito ao preço do serviço de qualquer fator, este permanece como indicador ou índice da sua escassez relativa de acordo com a restrição dos recursos à produção. De maneira geral, a razão entre os custos de oportunidade de dois bens nunca é menor do que a taxa marginal de substituição no consumo.

Têm-se então dois resultados. Produção, no sentido técnico, é o processo unidirecional de transformação de insumos em bens. Note-se que esta concepção da produção, enquanto processo unidirecional ao diferenciar insumos de bens, não pode dar expressão as idéias de reprodução e de produto líquido (quanto mais da distribuição deste produto entre classes econômicas). No interior do quadro teórico do modelo de equilíbrio geral, produção é somente uma etapa intermediária do processo principal de alocação de recursos para atender necessidades humanas, ou seja, configura apenas uma troca indireta de insumos por produtos finais. A condição de possibilidade permanece central ao modelo, embora agora inclua 0 conjunto de possibilidades de produção, determinado pelas restrições dos recursos.

\section{EM BUSCA DA EQUAÇÃO "PERDIDA"}

A etapa final do argumento de Hahn (1982, p.363-69) inicia-se pela especificação de uma equação que contenha apenas a taxa de lucro como variável a ser determinada. A fim de obter esta equação "perdida", Hahn considera um "ciclo anual" de produção. No modelo marginalista isto significa que, no mesmo período de tempo, a economia tem quantidades iguais de insumos que serão usadas (totalmente ou não) na produção de 
bens para os periodos seguintes (entretanto, as decisões para assim proceder serão tomadas no período corrente). Para isto, diferenciam-se os bens econômicos não somente pelo seu aspecto de valor de uso, mas também pela sua disponibilidade no tempo (e mais geralmente, no espaço). Considerando somente dois periodos de tempo, $t=1,2$, no modelo de dois bens acima, teremos quatro bens (dois bens em cada um dos dois períodos de tempo) e cinco preços (os preços dos quatro bens e a taxa de salário). $O$ vetor $Q=\left(p_{i}^{t}, w\right), i=1,2$ e $t=1,2$ é o parâmetro relevante para cada produtor maximizador de lucro.

No modelo marginalista, em geral, os preços relativos entre os dois bens não são os mesmos entre dois períodos de tempo, isto é:

$$
\frac{\left(p_{1}^{1} / p_{2}^{1}\right)}{\left(p_{1}^{2} / p_{2}^{2}\right)} \neq 1
$$

Definindo $\mathrm{R}_{\mathrm{i}}=\mathrm{p}_{\mathrm{i}}^{1} / \mathrm{p}_{\mathrm{i}}^{2}=1+\mathrm{r}_{\mathrm{i}}$, a própria taxa de retorno do bem $\mathrm{i}$ como a quantidade do bem i no tempo 2 a qual é possivel comprar com uma unidade do mesmo bem no tempo 1. Agora, para um indivíduo, a troca indireta do bem $i$ entre os dois períodos de tempo deve ser igual à troca direta (note que por "troca indireta", Hahn inclui o processo de produção). Então,

$$
\left(p_{1}^{1} / p_{2}^{1}\right)\left(p_{1}^{2} / p_{2}^{2}\right) R_{2}=R_{1}
$$

Se os preços relativos dos dois bens entre os dois periodos de tempo permanecem os mesmos (sua proporção é igual a 1 quando $R=0$ na equação (11) acima, então $R_{2}=R_{1}=R$ na equação (12)). Este resultado será importante mais tarde.

A expressão para os preços dos bens no periodo 2 é dada por:

$$
p_{j}^{2}=\sum a_{i j} p_{i}^{1}+a_{0 j} w, \quad j=1,2
$$

E o modelo completo será dado pelas seguintes equações: 


$$
\begin{aligned}
& \Pi_{i}\left(Q^{0}\right)=0 \\
& x_{i}^{1}\left(Q, \overline{x_{j}}\right)=0 \\
& \sum_{i} p_{i}^{t}+w=1
\end{aligned}
$$

A expressão (15) acima mostra a diferença entre a demanda pelo bem i e sua dotação inicial. Esta equação assume implicitamente a lei de Walras. Não é necessário considerar o mercado de trabalho porque, como o modelo tem somente três mercados (dois para cada bem e um para trabalho), se dois dos três estão em equilíbrio, então o terceiro também estará. A equação (15) também leva em consideração as preferências dos agentes através do excesso de demanda para qualquer bem.

Com estas nove equações, se há uma solução, serão determinados todos os preços de equilíbrio, as técnicas de produção, a composição do produto no período $2 \mathrm{e}$, finalmente, tomando um dos dois bens como numerário, é possivel calcular as taxas próprias comuns de retorno de cada bem em termos do numerário.

Para Hahn, o modelo sraffiano é somente um caso especial deste último modelo (equações 14 a 16). Em primeiro lugar, porque Sraffa não mostra como as técnicas em uso são obtidas. No modelo marginalista, Hahn argumenta que o conjunto de técnicas utilizadas são explicadas através da escolna racional de empresários que maximizam seus lucros. Em segundo lugar, como Sraffa assume que são invariantes os preços relativos dos dois bens entre dois períodos de tempo, então $R_{i}=R$ e os preços são dados por $p_{j}=R \Sigma a_{i j} p_{j}+a_{0 j} w$. A equação (16) acima torna-se:

$R p_{1}+R p_{2}+p_{1}+p_{2}+w=1$

Neste ponto, o modelo está sobredeterminado desde que as incógnitas foram reduzidas de cinco para quatro $\left(p_{1}, p_{2}, w, R\right)$. Isto significa que se um conjunto de preços e salário (o vetor $Q^{0}$ ) resolve a função de lucro unitário e a normalização acima, mas não pode satisfazer $R_{i}=R$, então o modelo não terá solução em absoluto. A única maneira de superar este caso especial é procurar um conjunto de dotações iniciais dos dois bens em questão para o qual $R_{i}=R$ se mantém. Hahn coloca uma forte ênfase neste passo, dizendo que "this question must be fixed whether you are a neoRicardian or not". De fato, este é o último ponto que abrirá a porta para as duas "especializações" no modelo marginalista pela qual a equação "perdida" é introduzida para determinar R, Hahn (1982, p.365-67). Estas "especializações" não serão discutidas aqui. $O$ único ponto importante é observar que, para Hahn, estas "especializações" não alteram qua!quer condição da produtividade marginal dada pela equação (8) acima. O 
restante desta seção examina o conteúdo conceitual da idéia de ciclo anual, introduzida por Hahn e da sua relação, se alguma existe, com a idéia de circularidade do sistema econômico de Sraffa.

Observou-se acima que a concepção marginalista da produção exclui conceitualmente as idéias de reprodução e produto líquido, idéias tão caras ao pensamento clássico. Então, como tal modelo pode gerar respostas ao modelo de Sraffa que se apoia precisamente nestas idéias? $O$ procedimento utilizado por Hahn funda-se numa segunda extensão do modelo marginalista. No modelo de trocas indiretas, construído para dar conta do fenômeno da produção, dados os seus parâmetros básicos (dotação inicial de recursos e preferências dos consumidores) determinamse as quantidades de serviços de fatores e de bens, e seus respectivos preços relativos referentes a um mesmo período de tempo. A generalização deste modelo ocorre quando se considera que os bens podem ser especificados não só pelas suas propriedades físicas, mas também pela sua disponibilidade no tempo e no espaço. Considerando-se apenas o aspecto temporal. Os bens passam então a serem 'datados', de tal forma que um quilo de arroz em 1997 é um bem distinto de um quilo de arroz em 1998. Esta "generalização" não altera em nada a lógica da análise econômica anterior e que se encontra já presente no modelo mais simples, o de trocas puras, (Bliss, 1975, p.46). Só que agora, o ato de economizar refere-se aos planos de produção e consumo dos agentes para vários periodos de tempo. As trocas envolvem decisões dos agentes sobre a alocação dos recursos disponiveis num período de tempo para atender suas preferências numa sequiência finita ou infinita de periodos de tempo. As trocas são intertemporais, mas são ainda trocas. Se os planos dos agentes são consistentes, então existe um conjunto de quantidades e preços "datados" que equilibram os mercados presentes e futuros de fatores e bens. Os preços refletem agora a escassez relativa dos bens e fatores de acordo com as preferências intertemporais dos agentes. Uma vez determinado este conjunto de preços, determina-se também o conjunto de taxas próprias de juros para os diversos pares de bens. Se estas taxas têm algum significado para a teoria marginalista é uma questão controversa. Para alguns autores, como Debreu $(1959$, p.32) e o próprio Hahn, sem dúvida, a "generalização" do modelo de equilíbrio geral obtida com a especificação temporal dos bens é um passo significativo para a introdução do tempo na análise e, com isto, habilitar a teoria marginalista para tratar dos problemas do capital e da sua acumulação. Para outros, como Koopmans (1957, p.120), não é claro o significado teórico destas taxas numa economia que não inclui crédito. De qualquer forma, o fato é que estas taxas de retorno são um subproduto da determinação dos preços relativos quando as trocas são intertemporais. Elas são, por assim dizer, 
derivadas do conjunto de preços relativos de equilíbrio que nada mais são do que indicadores da escassez relativa dos bens. Conforme apontam Walsh e Gram (1980, p.234-37), aqui se encontra o nó da questão. De forma alguma estas taxas estão relacionadas à existência de quantidades excedentes de produtos na esfera de produção e, portanto, não são conceitualmente equivalentes à idéia da taxa de lucro do modelo de Sraffa. Para este último, conforme ressaltou-se acima, a questão da determinação da taxa de lucro e de maneira geral, a questão distributivista, emerge quando o sistema de produção é estritamente viável, ou seja, quando o sistema de produção ao se reproduzir, reproduz também um excedente de produtos. Assim, embora Hahn consiga estabelecer uma aparente similaridade formal entre o modelo complexo de equilíbrio geral e o de Sraffa, ele está longe de obter a similaridade conceitual necessária para que as respostas do primeiro modelo sejam respostas às questões do segundo.

\section{CONCLUSÃO}

A partir do exame do argumento de Hahn pode-se derivar duas conclusões. Em primeiro lugar, considere-se o sentido do argumento de Hahn. Para gerar o modelo de Sraffa como um caso particular do modelo de equilíbrio geral, Hahn teve de tornar mais complexo ou geral o modelo de trocas puras. Esta elevação no grau de complexidade de modelo é inevitável, pois em sua formulação original a concepção de econômico marginalista exclui o fenômeno da produção. De fato, a primeira "generalização" de Hahn está implícita no seu argumento e corresponde à introdução da produção no modelo original. Este passo consiste na idéia de produção como um processo unidirecional que transforma insumos em bens. Produção se coloca assim como uma etapa intermediária entre a dotação inicial de recursos e as quantidades desejadas pelos agentes, de acordo com as suas preferências. No mundo marginalista, a vida econômica continua a ser dada pelas trocas, só que agora por trocas indiretas entre a dotação de recursos por bens. Sem esta generalização, Hahn não poderia nem iniciar um diálogo com Sraffa, pois enquanto Sraffa estaria preocupado com a determinação de preços de produção e de uma taxa uniforme de lucro, Hahn teria de se contentar em explicar trocas de bens já produzidos não se sabe bem como. Mas, uma vez feita esta generalização, Hahn pode então enfocar o problema de Sraffa no interior do modelo de equilíbrio geral, partindo em busca da equação "perdida" para determinar a taxa de lucro. Para tanto, Hahn utiliza uma segunda generalização do modelo marginalista, a saber, a especificação dos bens de acordo com suas disponibilidades temporais além das suas 
características físicas. Esta "generalização", conforme ressaltado acima, é a via empregada pelo pensamento marginalista para tratar das questões relativas a taxa de juros, capital (tempo), e crescimento. ${ }^{22}$ Ela em nada altera o núcleo da análise marginalista do sistema econômico, pois agora trata-se de trocas intertemporais entre os agentes.

Tem-se então este resultado paradoxal: o modelo de equilíbrio geral deve se tornar cada vez mais complexo para apresentar o modelo de Sraffa como um caso especial. Ora, se existe alguma dificuldade teórica, ela se encontra do lado da teoria marginalista, pois somente tornando-se mais complexa que ela pode dar conta de um caso supostamente mais simples. Note-se que não se trata apenas de adicionar produção à estrutura original. $\mathrm{Se}$ assim o fosse, estariamos diante de uma mera ampliação da teoria. $\mathrm{Na}$ verdade, está-se diante de um problema teórico específico à teoria marginalista, e muito bem assinalado por Pasinetti (1977, p.25-6), a saber, o de tentar subsumir o fenômeno da produção ao fenômeno da troca desde que conceitualmente, o mundo econômico caracteriza-se pelos atos de troca entre individuos "economizadores". Daí, a necessidade inevitável de se "complicar" o modelo original e não simplesmente ampliá-lo. Esta última observação nos leva à segunda conclusão deste artigo.

Com a segunda generalização, Hahn propõe-se a determinar a taxa de lucro aquilo que, no seu entender, Sraffa descarta ou negligencia. Mas, pelo exposto acima, o conteúdo conceitual da resposta de Hahn é distinto daquele proposto pela Economia Política. De fato, no modelo de trocas intertemporais, por tratar-se de trocas, as variáveis relevantes são as quantidades e os preços relativos "datados". Somente com a determinação destes últimos é que se determinam as taxas próprias de juros. Em outras palavras, a determinação destas últimas é um subproduto do processo de determinação daqueles preços relativos. Neste caso, de forma alguma estas taxas guardam alguma relação conceitual com o problema posto por Sraffa. Para este, como vimos na primeira seção, a questão que se coloca é a de um sistema econômico que produz recorrencialmente em termos físicos um excedente de produção. Tal concepção implica que, além dos preços de produção, deve-se determinar uma taxa de lucro uniforme. Então, o conceito de taxa de lucro encontra-se relacionado a emergência de um excedente em termos físicos. A taxa de lucro é o "dual" da taxa de excedente do sistema de produção. Logo, o conceito de taxas próprias de juros enquanto expressão das decisões alocativas intertemporais dos agentes não quer dizer absolutamente nada com o problema posto pela

\footnotetext{
22 Seguindo Garegnani (1983), Milgate (1979) argumenta que esta segunda "generalização" constitui-se na verdade numa mudança da questão original que era a determinação de preços regulados por uma taxa de lucro uniforme.
} 
Economia Política. E nem poderia, pois as idéias de reprodução e excedente não têm espaço teórico no edificio marginalista. O objetivo de Hahn era mostrar que o modelo marginalista de equilíbrio geral pode fornecer respostas às questões elaboradas pelo modelo de Sraffa. No limite, Hahn tencionava mostrar que este último modelo é um caso particular do próprio modelo de equilibrio geral. Conforme argüido acima, esta tarefa dependia da especificação dos conceitos de "produção como reprodução" e de "excedente" no interior da estrutura teórica do modelo de equilíbrio geral. As respostas de Hahn a Sraffa seriam tão legítimas quanto mais estes conceitos guardassem alguma familiaridade teórica com aquele empregado por Sraffa. Infelizmente este não é o caso e, portanto, a tarefa de Hahn limitou-se a um mero exercício formal dentro do modelo de equilíbrio geral.

\section{BIBLIOGRAFIA}

ALLINGHAM, M. Value Londres: MacMillan, 1983

ARROW, K , HAHN, F.H. General Competitive Analysis. S.Francisco: Holden-Day, 1971.

BLISS, C.J Capital Theory and the Distribution of income. Amsterdam: N Holland, 1975.

DASGUPTA, A K Epochs of Economic Theory. Oxford: Basil Blackwell, 1985

DEBREU, G. Theory of Value New Haven: Yale University Press, 1959.

EAGLY, R. V. The Structure of Classical Economics. N.York: Oxford Univ. Press, 1974.

GAREGNANI, $P$. On a Change in the Notion of Equilibrium in Recent Works on Value and

Distribution. In J EATWELL e MILGATE, M. (eds), Keynes's Economics and the

Theory of Value and Distribution. New York: Oxford University Press, 1983:

GROENEWEGEN, P D A Re-interpretation of Turgot's Theory of Capital and Interest.

Economic Journal, june, p. 327-40, 1971

HAHN, F. The Neo-Ricardians Cambridge Journal of Economics v.6, n.4, p.353-74,

Londres, december 1982

Os Neo-Ricardianos. Trad de Roberto Camps de Moraes. Análise Econômica, Porto

Alegre Ano 9, Set 1991, n.16.

INGRAO, B; ISRAEL, G. The Invisible Hand Economic Equilibrium in the History of

Science Cambridge MIT Press, 1990

KAUDER, E Genesis of the Marginal Utility Theory from Aristotle to the End of the

Eighteenth Century. In: SPENGLER, J J. ; ALLEN, W.R. (eds), Essays in Economic

Thought Aristotle to Marshall, Chicago. Rand MC Nally and Company, 1960.

KOOPMANS, T. C. Three Essays on the State of Economic Science N York: M.Hill, 1957.

MARX K Capital. Trad de Ben Fowkes. Vol I Harmondsworth: Penguin Books, 1976.

Capital, Vol II. Trad : David Fernbach. Harmondsworth. Penguin Books, 1978.

MENGER, K Principles of Economics. Trad de James Dingwall e Bert F Hoselitz. New

York: New York University Press, 1981

MILGATE, M. On the Origins of the Notion of 'Intertemporal Equilibrium. Economica, v.46, p. $1-10,1979$

MILL, J (1826). "Elements of Political Economy" in D. N. Winch (ed), James Mill selected

Economic Writings, Chicago University Chicago Press, 1966.

(1848) Principles of Political Economy. Reprints of Economic Classics Fairfield:

Augustus M. Kelley Publishers, 1987. 
(1848) Da Definição de Economia Política e do Método de Investigação Próprio a Ela Os Pensadores. São Paulo: Abril Cultural, 1983.

MYINT, H. Theories of Welfare Economics. New York. A. M. Kelley, 1965.

PASINETTI, L. Lectures on the Theory of Production. N York Columbia Univ Press, 1977.

QUESNAY, F. Miscellaneous Extracts. In: MEEK, R.L. (ed.) The Economics of Physiocracy.

Cambridge: Harvard University Press, 1963.

ROBBINS, L... An Essay on the Nature and Significance of Economic Science. Londres MacMillan, 1984

SANTOS, R. C A Teoria do Capital de Turgot Mimeo, USP, 1996.

SCHUMPETER, J A History of Economic Analysis Oxford: Clarendon Press, 1954

SMITH, A An Inquiry into the Nature and Causes of the Wealth of Nations. In. MACFIE, AL; RAPHAEL, D.D (eds), Vol II, Glasgow Edition of the Works and Correspondence of Adam Smith. Indianapolis: Liberty Press, 1981.

Lectures on Jurisprudence In: MEEK, R.L., RAPHAEL, D.D., STEIN, P.G (eds), Vol. V, Glasgow Edition of the Works and Correspondence of Adam Smith Indianapolis: Liberty Press, 1982.

SOROMENHO, J Capital e Coordenação Intertemporal a Visão Austriaca. USP, 1996.

SRAFFA, P. Production of Commodities by Means of Commodities Cambridge: Cambridge University Press, 1960

TURGOT, A. R. J. (1766). Reflections on the Formation and Distribution of Wealth. In GROENEWEGEM, P.D. (ed.), The Economics of A. R. Turgot Netherlands: Martinus Nijhoff, The Hague, 1977.

WALRAS L. Elements of Pure Economics. Philadelphia: Orin Editions, 1984.

WALSH, V.; GRAM, H. Classical and Neo-Classical Theories of General Equilibrium. New York: Oxford University Press, 1980. 